ARTIGO

\title{
O que dizem os atores estratégicos sobre a relação entre o Sistema de Avaliação Educacional do Estado de Pernambuco e a qualidade educacional?
}

Maurílio Mendes da Silva ${ }^{a}$ Zélia Maria Soares Jófili b

\section{Resumo}

O presente artigo apresenta a análise do discurso de cinco diferentes atores educacionais estratégicos que compõem o percurso discursivo da política de avaliação educacional do estado de Pernambuco. A análise, embasada nos estudos de Fairclough, foca na resposta à seguinte questão: Quais as relações que você estabelece entre os índices do Saepe e a qualidade educacional? Observa-se que não há neutralidade nos discursos e, de forma consciente, ou não, há posicionamentos ideológicos subjacentes aos textos que são proferidos, inclusive sinalizando para a existência de embate contra-hegemônico em relação à mencionada política de avaliação.

Palavras-chave: Política de avaliação educacional. Análise do discurso. Qualidade educacional.

\section{As políticas educacionais sob a análise discursiva}

Ball, Maguire e Braun (2016), ao tratarem de pesquisas sobre políticas, criticam a denominação "pesquisa de implementação". Para eles, as políticas são interpretadas e materializadas de formas variadas pelos diferentes sujeitos nos múltiplos contextos e não apenas implementadas. Os autores utilizam o termo policy enactement para expressar a ideia de que as políticas são encenadas,

\footnotetext{
Secretaria de Educação de Pernambuco, Recife, PE, Brasil.

b Universidade Federal Rural de Pernambuco, Recife, PE, Brasil. 
no sentido de que os "atores educacionais" as interpretam e as materializam de diferentes e variadas formas.

Os atores educacionais que trabalham dentro, e em torno, das escolas têm representatividade nos seus respectivos papéis e é nas suas interações hierarquizadas, desordenadas ou banais que eles negociam significados e fazem acontecer as políticas educacionais, reinterpretando-as a partir dos seus referenciais.

As políticas educacionais são mais bem compreendidas nas diferentes relações sociais dos seus atores, por meio do complexo jogo de poder que se materializa via interações discursivas. O discurso perpassa múltiplos contextos, das instâncias educacionais centrais até o espaço escolar. Desvelar o papel dos atores que compõem o encadeamento discursivo ajuda-nos a compreender a difusão ideológica da política de avaliação em larga escala. No nosso caso, a do Sistema de Avaliação da Educação Básica de Pernambuco (Saepe).

O discurso assume um acentuado papel na constituição dos objetos do conhecimento, das estruturas conceituais, dos sujeitos e das relações sociais estabelecidas entre eles. Pressupondo que esses discursos são originados da interdependência de outros discursos - anteriores ou contemporâneos (FOUCAULT, 2016), consideramos a análise crítica do discurso (ACD), a partir da perspectiva de Fairclough, para a análise do recorte discursivo adotado.

Fairclough (2016) ressalta a importância de se considerar o processo constitutivo do discurso para a análise, pois, assim, melhor se compreende a produção, a transformação e a reprodução dos objetos. "Os processos constitutivos do discurso devem ser vistos, portanto, em termos de uma dialética, na qual o impacto da prática discursiva depende de como ela interage com a realidade pré-constituída" (FAIRCLOUGH, 2016, p. 91). Isso reforça a relação ativa entre o discurso e a realidade, o que implica considerar a linguagem como elemento de construção de significados dessa realidade.

A ênfase nas relações interdiscursivas tem importantes implicações para a análise de discurso, já que põe no centro da agenda a investigação sobre a estruturação ou articulação das formações discursivas na relação umas com as outras, dentro do que eu chamarei, usando um termo foucaultiano, ordens do discurso institucionais e societárias - a totalidade de práticas discursivas dentro de uma instituição ou sociedade, e o relacionamento entre elas (FAIRCLOUGH, 2016, p. 70). 
Cada uma das redes de práticas sociais, como por exemplo, a organização educacional de uma sociedade num dado tempo e espaço, possui configurações específicas que constituem uma ordem social. Incluso nessa ordem social, há aspectos discursivos que lhes são peculiares, o que Fairclough descreve como ordem de discurso:

Uma ordem de discurso é a estruturação social da diferença semiótica: um ordenamento particular das relações entre diferentes formas de produzir sentidos, como discurso, gêneros e estilos diferentes. Um dos seus aspectos é a dominância: a existência de formas dominantes ou centrais, enquanto outras se opõem a elas, sendo marginais ou "alternativas" (2010, p. 227).

Embora numa dada estruturação social haja uma ordem de discurso hegemônica que busca se legitimar como um padrão, sempre haverá contestações em relação a ela. Uma ordem de discurso não pode ser compreendida como um sistema fechado ou rígido, mas aberto a contestações nas interações concretas.

As políticas educacionais do seu contexto de influência até o contexto da prática se constituem em projeções de como as coisas deveriam, ou poderiam, ser (BALL; MAGUIRE; BRAUN, 2016). Essas formulações idealizam redes de práticas sociais possíveis para a materialização dos seus discursos.

As políticas de avaliação em larga escala têm se pautado em propósitos performativos. O intuito é reger a vida dos que trabalham em escolas e órgãos educacionais por meio dos índices, valendo-se de uma estrutura panóptica de gestão verticalizada que responsabiliza unilateralmente os atores educacionais (SORDI, 2017).

Considerando que o Saepe faz parte de um sistema formal de accountability, que "consiste em mensurar e codificar padrões de resultados e prever determinadas consequências quando se atingem ou não esses resultados" (AFONSO, 2010, p. 161) e que a "encenação" dessa política possa influenciar na construção de sentidos dos atores educacionais sobre a relação entre a política de avaliação e a qualidade educacional, optamos pela dialética do discurso para realizar nossa análise.

Na Tabela 1, apresentamos a descrição dos atores educacionais. A escolha baseou-se no encadeamento hierárquico das funções que, partindo do epicentro da política de avaliação, podem incidir e influenciar o currículo na ação do professor de Matemática do Ensino Médio. 
Tabela 1 - Descrição dos atores educacionais que constituem o recorte discursivo

\begin{tabular}{lcccc}
\hline Atores & Função & Lotação & $\begin{array}{c}\text { Formação } \\
\text { inicial }\end{array}$ & $\begin{array}{c}\text { Idade - } \\
\text { Tempo de } \\
\text { serviço (anos) }\end{array}$ \\
\hline Sujeito 1 & $\begin{array}{c}\text { Gerente de Avaliação } \\
\text { e Monitoramento das } \\
\text { Políticas Educacionais }\end{array}$ & $\begin{array}{c}\text { Secretaria de } \\
\text { Educação do Estado }\end{array}$ & Letras & $45-12$ \\
Sujeito 2 & $\begin{array}{c}\text { Gerente Regional de } \\
\text { Educação }\end{array}$ & $\begin{array}{c}\text { Gerência Regional de } \\
\text { Educação }\end{array}$ & $\begin{array}{c}\text { Ciências } \\
\text { Sociais }\end{array}$ & $56-28$ \\
Sujeito 3 & Professor Formador & $\begin{array}{c}\text { Gerência Regional de } \\
\text { Educação }\end{array}$ & Matemática & $41-16$ \\
Sujeito 4 & Gestora Escolar & $\begin{array}{c}\text { Escola de Referéncia } \\
\text { em Ensino Médio }\end{array}$ & Matemática & $52-34$ \\
Sujeito 5 & Professor Regente & $\begin{array}{c}\text { Escola de Referência } \\
\text { em Ensino Médio }\end{array}$ & Matemática & $43-24$ \\
\hline
\end{tabular}

Fonte: Elaborada pelos autores (2019)

Passone (2019, p. 949) aponta que "a tecnocracia fundada no discurso cientificista e o poder gerencial têm ampliado seu domínio sobre o saber, o saber-fazer e o saber-ser dos profissionais da Educação", o que tende a influenciar o ordenamento discursivo dentro das, e entre, as instituições, atribuindo novos sentidos às interpretações dos seus atores.

\section{A avaliação em larga escala no cenário nacional}

No Brasil, segundo Luz (2018), pode-se atestar a ascensão do neoliberalismo e as suas repercussões em diversos campos, dentre eles a Educação:

O avanço das ideias neoliberais e a adoção efetiva de modelos econômicos, políticos e sociais, são consequências do ajuste do país à nova ordem mundial. Essas mudanças trazem à tona novos conceitos, como competências, competitividade, entre outros, estabelecendo um vínculo entre Educação e processo produtivo e fortalecendo o papel do mercado como regulador das relações sociais (p. 17).

Esse modelo administrativo impacta na organização educacional do país, inclusive na produção das regulamentações da área. A Constituição Federal de 1988 (BRASIL, 1988) menciona no seu artigo 206, inciso VII, que o ensino ministrado terá como um dos seus princípios a garantia de padrão de qualidade, sinalizando para a implantação de mecanismos que possam avaliá-lo e monitorá-lo. A Lei de Diretrizes e Bases da Educação Brasileira (LDB) de 1996 (BRASIL, 1996), 
artigo $9^{\circ}$ (inciso VI), traz menções voltadas ao processo nacional de avaliação educacional e à consequente melhoria da qualidade do ensino.

Ao organizar a sociedade e ao assumir o papel intervencionista, o Estado interfere em diversos aspectos da vida econômica, social e política das pessoas, inclusive na Educação ofertada pelos entes federativos, monitorando-a a partir de processos avaliativos nacionais, no intuito de garantir sua "qualidade".

Para Silva (2015), temos assistido à transformação de questões de cunho político e social da Educação em questões de ordem técnica. Os fatores sociais que acarretam déficits nessa área são subestimados, enquanto o discurso voltado à performatividade e à responsabilização ganham força, tudo em nome de uma pretensa ideia de qualidade educacional. Para Sá (2018, p. 805):

Reconhecer a complexidade do objeto avaliado e a natureza política do ato de avaliar constituem um primeiro requisito para frenar certos ímpetos tecnocráticos e gerencialistas que animam determinadas versões do Estado Avaliador, abrindo espaço para pensar práticas avaliativas mais reflexivas e dialógicas, sensíveis à polifonia de vozes que habitam no território escolar.

A Educação não pode deixar de ser pensada como uma construção social vinculada a uma perspectiva democrática para ser vista como "mercadoria" de consumo individual.

\section{Diferentes perspectivas da qualidade educacional}

O termo "qualidade" pode submeter-se a diferentes interpretações e, para ser bem compreendido, precisa estar relacionado às demandas de processos sociais específicos de uma dada época. Elencaremos alguns elementos que nos ajudarão a clarificar diferenças entre as perspectivas: qualidade total e qualidade social, ambas no âmbito educacional.

A qualidade total, termo oriundo do mundo empresarial, pode ser definida como um fator transfuncional, que perpassa diferentes dimensões da organização educacional, sendo certificada por diferentes entidades, segundo parâmetros amplamente consensuais, sem que sejam totalmente coincidentes. Estêvão (2013) critica a transferência do arsenal de procedimentos pensado e construído com fins de qualidade produtivista para o campo educacional, fincado num isomorfismo entre a Educação e o mundo industrial: 
Os defensores da qualidade a todo o custo investem neste novo modismo, procurando transferir quase toda a tecnologia da qualidade oriunda, ou pelo menos influenciada, pelas teorias administrativas e organizacionais de radical empresarial, convencidos de que estão que, deste modo, colocarão a Educação em estado de redenção (ESTÊVÃO, 2013, p. 19).

A adoção e a atenção exacerbada às medidas e aos padrões de performance, à publicação de rankings das escolas para a construção de imagens favoráveis ou desfavoráveis, à profissionalização dos gestores educacionais embasada na lógica empresarial e à competição por bônus são algumas das estratégias que têm emergido como o caminho mais acessível à tal qualidade.

Ball (2001, p. 106) preocupa-se com as articulações promovidas pelo conjunto de tecnologias políticas que instituem novos valores, novas relações e novas subjetividades nas arenas da prática educacional, pois o cenário que se desenha é propício ao desenvolvimento da cultura do autointeresse nas instituições educacionais, inclusive nas escolas, na qual "as motivações pessoais sobrepõem-se aos valores impessoais", o que fomenta a competição e os valores advindos dela e proporciona o distanciamento das questões de cunho social e educacional, presentes no seio da comunidade.

As escolas tendem a se voltar à concretização das metas propostas pelas instâncias centrais, a partir das quais são controladas, relegando questões formativas relevantes. As tecnologias políticas não mudam apenas as organizações escolares nos seus aspectos técnicos e estruturais, impactam também no que se faz e no que se é. O gerenciamento e a performatividade empregados para este fim propõem estados de desempenho e perfeição inalcançáveis.

Segundo Ball (2005), o gerenciamento é o mecanismo central das reformas políticas e o principal artifício para a reformulação dos serviços educacionais - uma força transformadora que insere uma cultura empresarial competitiva no setor público. Para ele, "o gerencialismo desempenha o importante papel de destruir os sistemas ético-profissionais que prevaleciam nas escolas, provocando sua substituição por sistemas empresariais competitivos" (BALL, 2005, p. 544). Por meio das avaliações, e consequentes bonificações, é exercido de forma cada vez mais ampla o controle administrativo. $\mathrm{O}$ gerenciamento conduz à busca pela performatividade:

A performatividade é uma tecnologia, uma cultura e um método de regulamentação que emprega julgamentos, comparações 
e demonstrações como meios de controle, atrito e mudança. Os desempenhos de sujeitos individuais ou de organizações servem de parâmetros de produtividade ou de resultado, ou servem ainda como demonstrações de "qualidade" ou "momentos" (grifos do autor) de promoção ou inspeção (BALL, 2005, p. 543).

A performatividade, materializada por meio da construção e da publicação de índices, constitui-se como instrumento de comparabilidade, possibilitando o ranqueamento das escolas e, por consequência, o comando dos seus respectivos contextos.

O gerenciamento e a performatividade propõem uma forma superficial de descrição daquilo que se faz no âmbito escolar. Apesar de parecerem sedutoras no que tange ao alcance da excelência educacional, tais tecnologias são incapazes de descrever a complexidade educacional.

A performatividade requer uma resposta dos atores educacionais, a accountability - termo que remete à responsabilização pelo desempenho dos alunos nas avaliações institucionais.

Afonso (2010) faz menção aos atos que estruturam a accountability: informação, justificação e sanção, os quais, embora possam surgir isoladamente, só adquirem força se atuarem de forma integrada. Exercitar a accountability é desenvolver uma ordem discursiva no meio onde é aplicada. O autor sugere uma tipologia que distingue os seus diferentes formatos: formas parcelares da accountability (ações que dizem respeito a apenas algumas dimensões), modelo de accountability (estrutura mais complexa, aberta e dinâmica, com relações e intersecções congruentes entre formas parcelares) e sistema de accountability (articulação entre formas parcelares com especificidades e diferentes graus de autonomia, nos quais o Estado age e orienta as políticas públicas a partir dos seus valores e princípios).

A accountability ocasiona o que Ball (2010) chama de "fabricações", a priorização de representações particulares, dentro de uma gama de versões aceitáveis, produzidas propositalmente em virtude de escolhas políticas.

Por meio dessas "fabricações", indivíduos e organizações podem parecer mais fortes e produtivos do que realmente são - tudo em nome de uma aproximação da performance desejável. "Um dos desdobramentos lógicos da imposição autoritária de qualquer meta inatingível é a proliferação de todo tipo de expediente de 
questionável validade ética com vistas a simular o alcance daquela" (BASTOS, 2018, p. 423). Se ocorrerem manipulações de dados para a construção das performances, os consumidores do "mercado educacional" acabam por acessar informações que destoam da realidade. Ball aponta um paradoxo: "Instituições educacionais se transformarão no que quer que seja necessário para florescer no mercado. $\mathrm{O}$ cerne do projeto educativo é arrancado e esvaziado. A autenticidade é substituída pela plasticidade" (BALL, 2010, p. 45).

A opção pela avaliação educacional pautada no modelo da qualidade total revela uma compreensão de Educação, cujo objetivo é qualificar para a competição do mercado de trabalho e para a produção de mão de obra de baixo custo. Gadotti (2013, p. 13) considera a mercantilização uma ameaça à qualidade educacional. Para ele, "o padrão mercantil do conceito de 'qualidade total' é o oposto do conceito de "qualidade social"".

Sordi (2017) defende uma escola pública com qualidade social, que preze por uma matriz de formação humana e omnilateral e que esteja assentada na construção de um mundo melhor, cultural e socialmente mais justo, onde as responsabilidades coletivas se sobreponham aos interesses individuais.

Compreendendo a Educação como uma prática social e um ato político, a qualidade social deve prezar pela inclusão, pela valoração e pela participação de todos os cidadãos na estruturação de uma sociedade mais igualitária, que favoreça a emancipação humana.

Para Cabrito (2009), a avaliação da qualidade educacional só faz sentido se tiver propósito formativo, identificar os problemas e contribuir para a sua reversão.

É inadmissível comparar médias de notas ou taxas de aprovação entre duas escolas que apresentam diferenças significativas em factores tão diversos e importantes como a origem social e econômica dos alunos, a qualidade dos equipamentos, a efectividade e qualificação dos docentes, a acessibilidade ou a localização geográfica (p. 195).

As discussões sobre qualidade educacional têm de estar atreladas à função social da escola. Bauer (2017, p. 78) alerta-nos para o fato de que "discutir metas, sem discutir problemas basilares relativos à escola e ao sistema educacional pode ter efeitos contrários aos objetivos que se quer chegar: o alcance da qualidade do ensino, da escola, da Educação". 
Dalben e Almeida (2015, p. 16) consideram que "as avaliações de larga escala deveriam ser parte da análise e não a principal medida utilizada na avaliação das instituições escolares". Nem toda aprendizagem dos alunos acontece no espaço escolar, o nível de proficiência atingido pelos alunos não depende integralmente da escola e dos professores, já que fatores extraescolares agem contribuindo, ou dificultando, o acesso ao conhecimento. Os autores consideram que as avaliações externas levam ao reducionismo do processo pedagógico.

Casassus (2009) considera que a política de avaliação estandardizada como instrumento de melhoria da qualidade educacional tem fracassado e aponta como um dos principais motivos o fato de nunca ter deixado claro o que se entendia por qualidade da Educação. Para ele, a finalidade educacional é melhorar as pessoas e a sociedade às quais pertencem. Segundo o autor, "os sistemas centralizados de medição afastam os sistemas educativos das finalidades para os quais foram criados" (CASASSUS, 2009, p. 73).

Uma das questões cruciais que deveria permear a discussão sobre qualidade educacional, que seria a finalidade da Educação, infelizmente permanece tímida ou ausente. Avaliar a sua qualidade sem avaliar a sua finalidade torna-se uma ação, no mínimo, imprecisa e até danosa.

\section{Considerações sobre o Sistema de Avaliação Educacional de Pernambuco (Saepe)}

O primeiro governo de Eduardo Campos, iniciado em 2007, implantou o modelo de gestão "Todos por Pernambuco" que propôs um conjunto de inovações, visando ao aperfeiçoamento da capacidade institucional, com foco na eficiência, na eficácia e na efetividade das ações governamentais. Na Educação, criou-se o Índice de Desenvolvimento de Educação de Pernambuco (Idepe) e reestruturou-se o Saepe. O Idepe, pautado nas variáveis fluxo escolar e proficiência, ganhou o status de qualificador educacional de Pernambuco.

O Estado passou a diagnosticar e a avaliar, anualmente, o desempenho de cada escola, ação que fortaleceu um modelo gerencial de gestão com foco em resultados que são tomados para a formulação de políticas públicas, orientando o planejamento e a reestruturação de diversas ações na área educacional.

Dentre essas ações, temos a assinatura do Termo de Compromisso pelos gestores escolares, que pactua metas relacionadas à promoção da melhoria dos indicadores educacionais observados a partir do Idepe. Tal Termo constitui-se como instrumento 
de monitoramento da gestão escolar e guia o funcionamento das instituições, intervindo nos processos administrativos e pedagógicos. As unidades escolares que atingem as metas pactuadas no Termo de Compromisso recebem o Bônus por Desempenho Educacional - BDE.

Se a finalidade é avaliar para melhorar a qualidade educacional, pautada na premissa da garantia de bons serviços públicos aos cidadãos, cabe ao Estado abrir espaços participativos de discussão a respeito dos propósitos da Educação ofertada, da funcionalidade dos testes aplicados e da anatomia da qualidade propagada.

\section{A concepção tridimensional do discurso na ACD de Fairclough}

O que torna a prática notadamente discursiva é a linguagem, manifesta linguisticamente por meio dos textos (falados ou escritos). Os textos constituem uma dimensão do evento discursivo, da mesma forma que a prática social. A prática discursiva é uma forma particular da prática social. Os processos sociocognitivos baseados nas estruturas e nas convenções sociais já interiorizadas guiam a produção e a interpretação textual.

Para uma compreensão mais ampla, é importante que os discursos sejam analisados numa perspectiva tridimensional, atentando para as articulações entre o texto, a prática discursiva e a prática social, conforme Figura 1.

Figura 1 - Concepção Tridimensional do Discurso

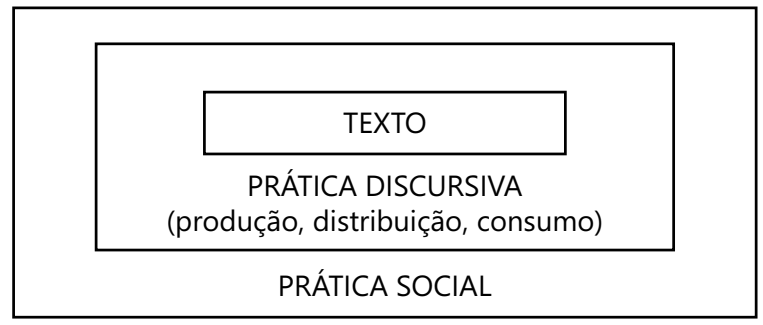

Fonte: Fairclough (2016, p. 105)

De acordo com Fairclough (2016), a análise textual organiza-se em quatro itens: estrutura textual, coesão, gramática e vocabulário. 
A estrutura textual relaciona-se ao planejamento e à construção do texto e busca enfatizar o modo e a ordem em que os seus elementos ou episódios são organizados. Esse processo organizacional possibilita pressupor traços identitários e relacionais que podem estar implícitos nas convenções do texto analisado.

A coesão busca apreender como se dão as ligações entre os elementos textuais - como as orações são ligadas em frases e como essas frases se estruturam para construir o texto. $\mathrm{O}$ estudo dessas articulações possibilita compreender a estrutura argumentativa do texto, possibilitando diferenciá-los.

A gramática tem como principal unidade a oração. Considerando que toda oração é multifuncional, ela acaba por desvelar combinação de significados ideacionais, interpessoais e textuais. Ao adotar um dado modelo ou estrutura, a pessoa acaba por transparecer vestígios da sua identidade social, das suas crenças e das relações sociais que estabelece num dado contexto.

O sentido do vocabulário no processo de análise do texto vai além daquele associado ao glossário. A sua acepção é na ideia de lexicalização (significação) do mundo, do sentido da palavra e do uso de metáforas particulares, componentes que remetem a certas peculiaridades de quem os utiliza. As opções léxicas incutem sentidos políticos e ideológicos que atribuem significado ao discurso e servem como foco de análise.

Fairclough (2016) afirma que a prática discursiva envolve processos de produção, distribuição e consumo textual, cuja natureza é influenciada por fatores sociais, como o contexto, por exemplo.

O conceito de produtor textual não é fácil de ser delineado, já que muitas vezes a produção de um texto pode ser realizada por uma ou mais pessoas ou tem origem noutro espaço. É importante considerarmos que em determinadas situações, como nas políticas educacionais, os textos são produzidos de forma a antecipar a sua distribuição e o seu consumo.

A distribuição dos textos acontece de formas distintas. Pode ser por meio de uma distribuição simples, como numa conversa informal, mas pode ter uma distribuição mais complexa, como no caso de uma campanha partidária. Existe a possibilidade de o discurso original ser transformado numa versão consumível por meio de outras instâncias, de acordo com os hábitos e com as rotinas peculiares dos seus receptores.

O consumo dos textos depende dos contextos nos quais são veiculados. Um texto só fará sentido para alguém se esse leitor for capaz de interpretá-lo. 
A dimensão prática social diz respeito à relação entre o discurso, a ideologia $\mathrm{e}$ o poder. O discurso aqui é considerado como uma forma de poder voltado ao estabelecimento da hegemonia de um dado objeto, mas considerando a possibilidade de luta hegemônica.

Fairclough (2016) toma como base teórica três asserções sobre ideologia: tem existência material nas práticas das instituições; "interpela os sujeitos" e, dessa forma, os discursos ajudam a constituí-los; e os "aparelhos ideológicos do estado" se constituem como instâncias delimitadoras na luta de classe. Os discursos não são neutros. Para o autor:

As ideologias são significações/construções da realidade (o mundo físico, as relações sociais, as identidades sociais), que são construídas em várias dimensões das formas/sentidos das práticas discursivas e que contribuem para a produção, a reprodução ou a transformação das relações de dominação (FAIRCLOUGH, 2016, p. 122).

As ideologias ganham eficácia quando são embutidas nas práticas discursivas e se naturalizam de tal forma que passam a ser agregadas ao senso comum. Porém, para o autor, o foco de estudo e o que deve ser enfatizado não é o conformismo com o estabelecido, mas a luta ideológica que busca construir a transformação das relações de dominação por meio da prática discursiva. Quanto ao lugar da ideologia nesses processos, o autor assim se expressa:

Prefiro a concepção de que a ideologia está localizada tanto nas estruturas (isto é, ordens do discurso) que constituem o resultado de eventos passados como nas condições para os eventos atuais e nos próprios eventos, quando reproduzem e transformam as estruturas condicionadoras (FAIRCLOUGH, 2016, p. 124).

A partir desse entendimento, a ideologia pode ser tomada como uma propriedade tanto das ordens do discurso, vinculada a eventos precedentes, quanto dos eventos, relacionados às suas condições presentes.

\section{O que nos revela a análise do recorte discursivo}

A análise discursiva, embasada na tridimensionalidade do discurso, presente na ACD de Fairclough, realizou-se sobre as respostas das entrevistas semiestruturadas acerca das relações estabelecidas pelos atores entre o Saepe e a qualidade educacional. Não há procedimento fixo para fazer a análise do discurso, as pessoas 
que adotam essa orientação a abordam de maneiras distintas, dependendo do objeto de pesquisa e da visão do discurso adotada.

Fairclough (2016) fala da superposição das dimensões nos três níveis de análise: a macroanálise (práticas discursivas, focalizando a intertextualidade e a interdiscursividade das amostras dos discursos), a microanálise (análise dos textos) e a análise da prática social da qual o discurso é uma parte. Para o autor não há uma ordem específica por onde começar, isto depende dos propósitos e das ênfases da análise.

Como trabalhamos com entrevistas, partimos da descrição do texto à prática discursiva, situando-as na prática social mais ampla, em movimentos de idas e vindas, sem rigidez no processo, mas buscando "mostrar características, padrões e estruturas que são típicos de certos tipos de discurso" (FAIRCLOUGH, 2016, p. 295).

No que se refere às respostadas dadas à questão: Quais relações você consegue estabelecer entre os índices do Saepe e a qualidade educacional?

O sujeito 1 valeu-se de algumas metáforas para responder à questão:

Uma avaliação externa não é a "salvadora da pátria", ela é a "diagnose", ela é a "fotografia daquele momento", do que a gente quer coletar, para, a partir desses dados, a gente tomar decisão. [...] A partir dessa "diagnose" é que são implementadas as políticas públicas. [...] A relação do Saepe com a qualidade do ensino, sem dúvida nenhuma, é a contribuição de uma "diagnose", de um instrumento diagnóstico para a gente olhar para onde a gente quer caminhar, como a gente está e aonde a gente quer chegar (sujeito 1).

Tomando "salvadora da pátria" como capacidade de resolver tudo e "diagnose" como descrição minuciosa das razões de um problema circunstancial, o entendimento que se tem dessas duas metáforas é que, embora a avaliação, por si só, não consiga resolver tudo, ela é capaz de apresentar um quadro descritivo para subsidiar o planejamento de estratégias viáveis à resolução do problema. Por outro lado, a metáfora da "fotografia daquele momento" sugere uma imagem estática, incapaz de captar toda a dinamicidade do processo educativo (questões estruturais, contextuais...), ou seja, a avaliação não é suficiente para qualificar a complexidade educacional. Esses aspectos contraditórios resultam de uma hegemonia ainda não totalmente consolidada no discurso do sujeito, mas 
presente o suficiente para contorná-lo, como se percebe por meio da repetição da palavra diagnose.

Para Fairclough (2016, p. 250): “as metáforas não são apenas adornos estilísticos superficiais do discurso. [...] As metáforas estruturam o modo como pensamos e o modo como agimos, nossos sistemas de conhecimento e de crenças, de uma forma penetrante e fundamental".

Outro aspecto importante no fragmento anterior são as expressões "a gente tomar decisão" e "para gente ter aí um olhar para onde a gente quer caminhar" que remetem a quem está no comando e na responsabilidade de pensar o problema. Sugere o lugar social de quem fala dentro das relações discursivas. O lugar do "a gente", certamente, não é o lugar do professor e do aluno que estão lá na escola, mas do Estado que estipula metas e propõe políticas educacionais. A qualidade educacional pretendida é determinada por agentes externos ao contexto escolar, distanciando-se da abordagem da qualidade social da Educação.

O sujeito 2 também faz uso de metáfora na composição da sua resposta e o uso enfático da expressão "a gente" como o sujeito das ações.

O Saepe, para mim, é um "termômetro" para a gente saber como a gente está trabalhando com o estudante. Quando se faz a avaliação do Saepe e a gente vê que atingiu aquelas metas, a gente sabe que conseguiu alcançar os resultados que a gente pretendia (sujeito 2).

O "termômetro" remete a um instrumento que, apesar de identificar as condições febris de um paciente, não detecta a causa. De forma análoga, funciona o Saepe. Apesar de pontuar o nível de proficiência dos alunos nas habilidades de algumas disciplinas, não capta a complexidade dos motivos que conduzem ao referido indicador. A seguir, um fragmento complementar do sujeito 2 que associa os números do Saepe à repercussão das ações: "Através dessa avaliação é que a gente realmente sabe se a gente tá indo no caminho certo com a formação, com o acompanhamento na sala de aula, com as orientações que estão sendo dadas aos educadores de apoio" (sujeito 2).

A expressão "a gente realmente sabe se a gente tá indo no caminho certo" sugere a não participação dos atores escolares, inclusive professores, na idealização da via a ser seguida. Quem pensa as questões relacionadas à formação docente e às orientações gerenciais no campo pedagógico são o gerente e os técnicos, cujos comandos determinam as melhores estratégias de ação. 
A valorização dos indicadores do Saepe como referência para atestar os avanços educacionais e as tomadas de decisão pautadas neles são formas de materialização da política estatal que busca efetivar o caráter hegemônico da relação entre os seus elevados índices e o avanço da qualidade educacional pública.

O sujeito 3 reconhece a relevância do Saepe, mas considera que apenas os seus índices não são capazes de atestar a qualidade educacional: "Só a avaliação do Saepe em si, para mim, assim como a do Ideb não pode qualificar, como se estivessem dizendo que ali está tendo uma grande qualidade ou não, mas ela é sim um sinal forte" (sujeito 3 ).

O meio-termo apresentado pelo sujeito 3 no que se refere à relação entre Saepe e qualidade educacional constitui-se como uma moderação decorrente das suas circunstâncias profissionais. $\mathrm{O}$ discurso reflete uma busca de equilíbrio entre o profissional que lida com orientações mais firmes da política avaliativa e o que, em sala de aula, reconhece que há mais fatores e limites que influenciam a qualificação educacional. Da sensibilidade de quem vivencia experiências próximas, mas bem diferenciadas, emerge a percepção de elementos que podem questionar a amálgama Saepe/qualidade educacional. Seu discurso aponta possíveis vulnerabilidades:

Um exame em um ano não diz tudo pela fragilidade que é uma avaliação, porque pode ter tido um aplicador mais frágil ou pela escola estar vivendo um momento mais difícil, como a vivência de uma epidemia. [...]

Um município pode dizer assim: a partir de hoje o nosso currículo é a matriz do Saepe. Se ele resolver fazer uma loucura dessas, dependendo do trabalho, você pode ter elevados índices (sujeito 3).

A opção por um projeto educacional de orientação curricular limitada, que prioriza duas áreas de conhecimento em detrimento das outras, circunscrevendo, basicamente, seus conteúdos às matrizes de referência, e uma possível frouxidão na aplicação dos testes constituem-se como possíveis estratégias de "fabricação" de resultados e ele está ciente que esses eventos podem acontecer. Questionamos-lhe, então: o que seria qualidade educacional?

Qualidade educacional seria quando você tem uma Educação que consiga valorizar e respeitar todos os aspectos dos estudantes. [...] Incluir todos no processo de aprendizagem e emancipar o indivíduo. 
[...] Qualidade, para mim, é uma coisa muito abrangente quando a gente fala da Educação, e não voltada somente à questão de uma avaliação externa que a gente trabalha na ideia de um olhar linear. [...] Qualidade, para mim, é uma coisa bem mais ampla, qualidade tem que traduzir mudança social (sujeito 3 ).

Apesar de desenvolver ações formativas junto aos professores do Ensino Médio voltadas à melhoria dos índices do Saepe e mesmo reconhecendo a contribuição das avaliações em larga escala como indicativo de qualidade, o discurso do sujeito 3, aproxima-se de uma compreensão de avaliação educacional voltada à abordagem relacionada à qualidade social. Fairclough cita que "quando são encontradas práticas discursivas contrastantes em um domínio particular ou instituição, há probabilidade de que parte desse contraste seja ideológico" (2016, p. 122).

O sujeito 4 divagou, como se buscasse se expressar sem contradizer a política educacional. Refizemos a questão e, da sua segunda resposta, selecionamos o excerto: Nem sempre os resultados atestam qualidade educacional. "[...] Porque se fosse assim, dessa maneira, toda a escola que estivesse em alta iria se manter em alta e isso não acontece, porque a gente tem todo ano turmas diferentes sendo avaliadas e a gente recebe os nossos alunos com muitos déficits" (sujeito 4).

Vê-se que há variáveis externas que interferem no alcance das metas propostas e que escapam ao seu controle. Ainda que haja uma equipe de profissionais compromissada em contribuir para a melhoria dos resultados, esses empecilhos travam a consecução das metas. Vejamos: "Teve um ano que a gente passou. A meta era 4,1, a gente foi para 5,43. Então, a gente superou todas as metas. $\mathrm{O}$ trabalho que a gente fez foi o mesmo que foi feito no ano seguinte, mas a gente não teve o mesmo êxito" (sujeito 4).

O sujeito 4, ex-professor regente de Matemática, fala da conquista da equipe e reconhece a importância dos índices como uma forma de se apresentar bem perante o cenário educacional, mas atenta para o fato de que o sucesso é relativo, pois depende de fatores externos à escola. Apesar de discordar parcialmente em relação aos resultados do Saepe como forma de atestar qualidade, mostra-se preocupado em envidar esforços para o cumprimento das metas, efeito decorrente da função que exerce. Mesmo não sendo enfático na defesa do Saepe, credita importância às exigências do formato avaliativo do Estado, trazendo nuances da qualidade total no discurso. 
Para o sujeito 5, a orientação dos alunos para o Saepe contribui para o Enem e o Sistema Seriado de Avaliação - SSA, porém não a considera suficiente, já que o grau de dificuldade das questões desses outros testes é mais elevado. Seu entendimento sobre qualidade educacional está atrelado ao acesso dos alunos ao Ensino Superior. Ele relativiza a importância do Saepe como determinante da qualidade educacional:

Eu acredito que a qualidade da Educação não depende exclusivamente de um resultado de uma avaliação externa Ele (o Saepe) dá um indicativo. [...] Você, de certa forma, sabe que ele (o aluno) foi bem preparado, mas isso não é a única maneira de testar a qualidade da Educação. [...] Há alunos que conseguem desenvolver bem atividades em grupo. [...] Uma prova não vai mostrar o tipo de aluno que você tem, nem as suas outras habilidades, nem tampouco o tipo de instituição (sujeito 5).

Mesmo reconhecendo a contribuição do Saepe como um possível componente da aferição educacional, aponta insuficiências e contesta a caracterização de alunos e de instituições a partir desses índices.

Embora seu discurso não explicite claramente a sua filiação quanto à abordagem qualitativa da Educação, acreditamos que, por ele não se alinhar ao modelo avaliativo pautado apenas em testes e por reconhecer que a complexidade educacional abarca outros elementos, o situamos mais próximo da vertente qualidade social.

Os sujeitos 1 e 2 naturalizam o Saepe como qualificador educacional, o primeiro considerando-o como possibilidade para diagnosticar problemas educacionais e para traçar políticas públicas; o segundo, pela relevância atribuída às metas propostas pelo Estado. Os sujeitos 3, 4 e 5, de diferentes formas, e em diferentes níveis, apresentam evidências de posicionamento contra-hegemônico. Seus posicionamentos podem decorrer de inúmeros fatores, dentre eles, o fato de já terem exercido ou exercerem a regência em Matemática. Já experienciaram a cobrança por resultados na sua área de atuação e lidaram com a obstaculização de fatores externos na concretização das metas impostas, o que contribui para o entendimento da complexidade educacional.

Posicionamentos com traços discordantes em relação à política avaliativa remetem à existência de luta ideológica na arena da prática discursiva, o que pode possibilitar a redefinição das relações de poder e, consequentemente, ocasionar resistências. 


\section{Considerações finais}

O recorte discursivo analisado situa-se numa prática social, cuja finalidade é articular atores educacionais, a partir das suas diferentes funções, na execução da política de avaliação em larga escala. A estrutura relacional entre os sujeitos tem caráter formal e hierárquico, que parte da instância mais central, SEE-PE, atravessa a instância intermediária, GRE, até atingir a unidade escolar na qual a referida política busca se materializar.

Observa-se, a partir da instância central de gerenciamento, a propagação da ideia de que o Saepe se constitui como diagnóstico dos problemas educacionais, já que oferece informações necessárias ao replanejamento de ações capazes de garantir uma Educação Pública de qualidade.

Dentre os múltiplos efeitos dessa política, há demanda por resultados em série. A gerência de avaliação é cobrada e repassa a cobrança às gerências regionais que exigem dos gestores escolares ações de melhoria, impactando, em última instância, na condução do trabalho docente, que deve propiciar condições para o êxito dos alunos nos testes estandardizados.

Registramos traços identitários da função de alguns atores nos seus discursos: posicionamentos favoráveis mais consistentes, apreciações mistas - entremeadas por resquícios dos diferentes papéis vivenciados no percurso profissional e relutância ao que se propõe como instrumento de qualificação educacional.

Nos posicionamentos ideológicos subjacentes ao que foi proferido, também observamos que os atores educacionais lotados em funções de natureza gerencial tendem ao fortalecimento hegemônico do binômio Saepe-qualidade, enquanto os atores mais próximos dos espaços escolares, que lidam com o processo formativo docente e com o ensino, dão sinais de posicionamentos contra-hegemônicos.

Apesar da relevância do Saepe, consideramos que ele se pauta mais na política de gestão do sistema e menos na política de Educação. Emerge a necessidade por espaços coletivos de discussão sobre a finalidade e a qualidade educacional. Aliados a Casassus (2010), defendemos que uma Educação de qualidade remete à oferta de conhecimento transformador. 


\section{What do strategic actors say about the relationship between the Educational Assessment System of the State of Pernambuco and educational quality?}

\section{Abstract}

This paper presents the discourse analysis of five different strategic educational actors that make up the discursive path of the educational evaluation policy of the State of Pernambuco. The analysis, based on Fairclough studies, focuses on the answer to the following question: What relationships do you establish between Saepe indices and educational quality? It is observed that there is no neutrality in the discourses and, consciously or not, there are ideological positions underlying the texts that are given, including signaling the existence of a counter-hegemonic clash with the mentioned evaluation policy.

Keywords: Educational evaluation policy. Discourse analysis. Educational quality.

\section{¿Qué dicen los actores estratégicos sobre la relación entre el Sistema de Evaluación Educativa del Estado de Pernambuco y la calidad educativa?}

\section{Resumen}

Este artículo presenta el análisis del discurso de cinco diferentes actores educativos estratégicos que conforman la trayectoria discursiva de la política de evaluación educativa en el estado de Pernambuco. El análisis, basado en los estudios de Fairclough, se centra en dar respuesta a la siguiente pregunta: ¿Qué relaciones establece entre los indices Saepe y la calidad educativa? Se observa que no hay neutralidad en los discursos $y$, conscientemente o no, hay posiciones ideológicas subyacentes a los textos que se pronuncian, señalando incluso la existencia de un choque contrahegemónico en relación a la referida política de evaluación.

Palabras clave: Política de evaluación educativa. Análisis del discurso. Calidad educativa. 


\section{Referências}

AFONSO, A. J. Um olhar sociológico em torno da accountability em educação. In: ESTEBAN, M. T.; AFONSO, A. J. (orgs.). Olhares e interfaces: reflexões críticas sobre avaliação. São Paulo: Cortez, 2010. p. 147-170.

BALL, S. J. Diretrizes políticas globais e relações políticas locais em educação. Currículo sem Fronteiras, [s. 1.], v. 1, n. 2, p. 99-116, jul./dez. 2001.

BALL, S. J. Performatividades e fabricações na economia educacional: rumo a uma sociedade performativa. Educação \& Realidade, Porto Alegre, v. 35, n. 2, p.37-55, maio/ago. 2010.

BALL, S. J. Profissionalismo, gerencialismo e performatividade. Cadernos de Pesquisa, São Paulo, v. 35, n. 126. p. 539-564, set/dez. 2005. https://doi.org/10.1590/S0100-15742005000300002

BALL, S. J.; MAGUIRE, M.; BRAUN, A. Como as escolas fazem as políticas: atuação em escolas secundárias. Ponta Grossa: Editora UEPG, 2016.

BASTOS, R. M. B. O papel dos testes padronizados na política educacional para o ensino básico nos Estados Unidos. Ensaio: Avaliação e Políticas Públicas em Educação, Rio de Janeiro, v. 26, n. 99, p .418-444, abr./jun. 2018. https://doi.org/10.1590/S0104-403620180026000993

BAUER, A. Uso de indicadores educacionais para a avaliação e monitoramento da qualidade da escola: possibilidades e desafios. In: SORDI, M. R. L.; VARANI, A.; MENDES, G. S. C. V. (orgs.). Qualidade(s) da escola pública: reinventando a avaliação como resistência. Uberlândia: Navegando, 2017. p. 69-82.

BRASIL. Lei $\mathrm{n}^{\circ}$ 9.394, de 20 de dezembro de 1996. Estabelece as diretrizes e bases da educação nacional. Diário Oficial da União, Brasília, DF, 23 dez. 1996.

BRASIL. Senado Federal. Constituição da República Federativa do Brasil. Brasília, DF, 1988.

CABRITO, B. G. Avaliar a qualidade em educação: avaliar o quê? Avaliar como? Avaliar para quê? Caderno Cedes, Campinas, v. 29, n. 78, p. 178-200, maio/ago. 2009. https://doi.org/10.1590/S0101-32622009000200003 
CASASSUS, J. Uma nota crítica sobre a avaliação estandardizada: a perda de qualidade e a segmentação social. Sísifo / Revista de Ciências da Educação, Lisboa, n. 9, p. 71-78, maio/ago. 2009.

DALBEN, A.; ALMEIDA, L. C. Para uma avaliação em larga escala multidimensional. Estudos em Avaliação Educacional, São Paulo. v. 26, n. 61, p. 12-28, jan./abr. 2015. https://doi.org/10.18222/eae266103140

ESTÊVÃO, C. V. A qualidade da educação: suas implicações na política e na gestão pedagógica. RBPAE, Brasília, DF, v. 29, n. 1, p. 15-26, jan./abr. 2013. https://doi.org/10.21573/vol29n12013.42818

FAIRCLOUGH, N. Discurso e mudança social. 2. ed. Brasília, DF: Editora Universidade de Brasília, 2016.

FOUCAULT, M. A arqueologia do saber. 8. ed. Rio de Janeiro: Forense Universitária, 2016.

GADOTTI, M. Qualidade na educação: uma nova abordagem. In: CONGRESSO DE EDUCAÇÃO BÁSICA: QUALIDADE NA APRENDIZAGEM - COEB, Florianópolis, 2013. [S.n. t.].

LUZ, D. C. S. F. Educação corporativa: a proposta empresarial no discurso e na prática. Rio de Janeiro: Gramma, 2018.

PASSONE, E. F. K. Da avaliação em larga escala ao furor avaliativo: a degradação do ato educativo. Quaestio, Sorocaba, v. 21, n. 3, p. 945-964, set./dez. 2019. https://doi.org/10.22483/2177-5796.2019v21n3p945-964

SÁ, V. Avaliação institucional de escolas de Educação Básica em Portugal: políticas, processos e práticas. Ensaio: Avaliação e Políticas Públicas em Educação, Rio de Janeiro, v. 26, n. 100, p. 801-821, jul./set. 2018. https://doi.org/10.1590/S0104-40362018002601163

SILVA, T. T. A "nova" direita e as transformações na pedagogia da política e na política da pedagogia. In: GENTILI, P. A. A.; SILVA, T. T. (orgs.). Neoliberalismo, qualidade total e educação: visões críticas. 15. ed. Petrópolis: Vozes, 2015. p. 9-29.

SORDI, M. R. L. A qualidade social da escola pública em confronto com a lógica dos reformadores empresariais. In: SORDI, M. R. L.; VARANI, A.; MENDES, G. S. C.az. (orgs.). Qualidade(s) da escola pública: reinventando a avaliação como resistência. Uberlândia: Navegando, 2017. p. 83-100. 


\section{Informações sobre os autores}

Maurílio Mendes da Silva: Doutor em Ensino de Ciências e Matemática pela Universidade Federal Rural de Pernambuco. Professor da Educação Básica da Secretaria de Educação de Pernambuco. Contato: prof.mauriliomsilva@gmail.com

iD https://orcid.org/0000-0003-4509-4752

Zélia Maria Soares Jófili: Doutora em Educação pela Surrey University, UK. Professora do Programa de Pós-Graduação em Ensino de Ciências da Universidade Federal Rural de Pernambuco. Contato: zjofili@gmail.com

iD https://orcid.org/0000-0002-9244-2337 